\title{
NEUROPATHIC PAIN AND CHRONIC PAIN AS AN UNDERESTIMATED INTERDISCIPLINARY PROBLEM
}

\author{
ANNA K. SZEWCZYK, ANNA JAMROZ-WIŚNIEWSKA, NATALIA HARATYM, and KONRAD REJDAK
}

Medical University of Lublin, Lublin, Poland

Department of Neurology

\begin{abstract}
Neuropathic pain and chronic pain constitute an interdisciplinary problem on the border of medicine, psychology, sociology and economics. While it seems to be underestimated, the scale of this problem will continue to increase due to the population aging and the growing incidence of lifestyle disorders. People employed in various occupational sectors may also wrestle with these disease units, which affect the quality of their life, mental health and work productivity. A narrative review provided an overview of neuropathic pain and chronic pain, and their relationship to such factors as job type, work absenteeism and productivity decline, as well mental well-being. A systematic literature search was conducted based on the Preferred Reporting Items for Systematic Reviews and Meta-Analysis (PRISMA) guidelines to identify appropriate literature by searching the electronic databases: PubMed/MEDLINE, Pain Journal and the Cochrane Database of Systematic Reviews. Studies were published in Polish, English and French. Research shows an increasing number of musculoskeletal diseases in professionally active people, which lead to disability or provoke work absences. However, sickness presenteeism and/or absenteeism caused by pain not only leads to economic burdens, but also to burnout, fatigue and depression syndromes in employees. These disorders may require specialized effective interventions to support the return to work or maintaining employment despite experiencing pain. Every patient with chronic or neuropathic pain should be correctly assessed to determine the best method of treatment and its effectiveness. Int J Occup Med Environ Health. 2022;35(3):249-64
\end{abstract}

Key words:

treatment, epidemiology, chronic pain, neuropathic pain, occupational disorders, musculoskeletal pain

\section{INTRODUCTION}

Despite many years of research and development, neuropathic pain, as an intractable form of chronic pain, has not been completely understood yet [1]. Pain or "discomfort" is typically perceived in the area of innervation, which is somatotopically represented in the damaged structure at different levels of the central or peripheral nervous system [2]. Such damage may be the result of surgery treatment, injuries or chronic diseases, including diabetes, multiple sclerosis and stroke. Many patients struggling with the disease do not respond to treatment, poorly tolerate it or respond only partially, which makes pharmacologic treatment challenging $[1,3,4]$.
Neuropathic pain, more than chronic pain, has an impact on the quality of life, sleep efficiency, and the appearance of depressive disorders $[4,5]$. A more frequent use of health resources and increased drug prescriptions are also observed, while in professional life absenteeism and decreased efficiency are seen frequently, combined with lowered productivity [6,7], functional impairment, including mobility impairment, pain and fatigue [8]. It is assumed that the number of patients suffering from neuropathy and chronic pain is underestimated. It particularly concerns people with undiagnosed neurological diseases or without long-term treatment. More and more studies also report the occurrence of neuropathic and chronic

Received: June 11, 2020. Accepted: October 29, 2021.

Corresponding author: Anna K. Szewczyk, Medical University of Lublin, Department of Neurology, Jaczewskiego 8, 20-954 Lublin, Poland (e-mail: szewczyk.anna1@gmail.com). 
pain in occupational activity. An incorrect result may be influenced by various multifocal pain locations reported by patients. Likewise, pain may have different characteristics presented as a combination of pain sensations with and without neuropathic characteristics [4,9]. The addition of supplemental criteria for chronic pain and the reclassification of criteria for chronic neuropathic pain aim to increase the recognition of the problem, and to improve patient care and treatment, health policy decisions and financing, and research on pain and its accurate epidemiology.

\section{METHODS}

A systematic literature search was conducted based on the Preferred Reporting Items for Systematic Reviews and Meta-Analysis (PRISMA) guidelines [10] to select proper literature for this narrative review. An extensive literature search, including the following electronic databases: PubMed/MEDLINE, Pain Journal and the Cochrane Database of Systematic Review, was conducted to create a list of study abstracts for screening. Studies were published in Polish, English and French. Titles and abstracts of publications were found by searching for the following terms: "neuropathic pain," "chronic pain," "neuropathy," "chronic neuropathic pain," "epidemiology," "guidelines," "occupational disorders," "occupational diseases," "work absenteeism," "work return," "job quit," "work ability," "psychosocial factors," "musculoskeletal pain," "musculoskeletal diseases," and "depressive symptoms." The literature search covered the period of 2000-2021 which, according to the authors, should ensure a sufficient and up-to-date review of the literature.

The exclusion criteria included conference abstracts, posters, presentations and restricted access. Studies were also excluded if they were not published in a peerreviewed journal or were not available in Polish, English or French. Study selections were done independently to find original studies eligible for future reviews, following which full-text manuscripts were reviewed.
The original purpose of the work was to present and evaluate new diagnostic guidelines for chronic and neuropathic pain. However, while collecting the material, the urgent problem of pain disorders connected with the type of work performed was discovered. Finally, the review presents the epidemiology of chronic pain and neuropathic pain, their connections with work ability and absenteeism, as well as international and Polish recommendations for the diagnosis, management and treatment of chronic and neuropathic pain. Presented scales, tips and current recommendations may be helpful in the daily activity of an occupational physician. One of the work limitations is the small number of epidemiology reports based on the Polish population.

\section{Epidemiology}

Socio-demographic studies based on the French population show that, in the general population, the incidence of moderate to severe chronic pain is almost $20 \%$, of which nearly $22 \%$ of patients (namely, about $7 \%$ of the general population) have a neuropathic component [4]. Similar results for neuropathic pain, oscillating around 6-10\%, are obtained in non-European countries with the incidence at $8.2 / 1000$ person-years [5,11]. It is estimated that $15-20 \%$ of visits at physicians are caused by chronic pain. Moreover, patients with neuropathic components report more severe pain $[4,12]$.

Assessing the prevalence of chronic pain is very difficult because of the inconsistent definitions of chronic pain in epidemiological literature. This may reduce the importance of chronic pain as an essential health issue as well as complicate the evaluation of treatment and prevention $[2,13]$. Also, age-related disorders make it more difficult to assess the occurrence of chronic pain [14]. Therefore, personalized interventions and a multidisciplinary approach to the patient are often emphasized and needed [7]. Neuropathic pain is predominant in people living in rural areas, particularly among manual workers or farm- 
ers. Its occurrence increases with age and mainly affects women in the age range of 50-64 years [4]. Apart from older age and female sex, the occurrence of chronic pain is influenced by a low socio-economic status and educational level, unemployment, addictions and poor physical activity [14]. Areas of the body where pain is the most common include lower limbs and the back. Patients describe the occurrence of very severe pain simultaneously with partial or total sensory disturbances (the coexistence of hypersensitivity and hyposensitivity) $[15,16]$.

According to research pertaining to chronic pain conducted in Europe and Israel, chronic pain of moderate to severe intensity occurs in $19 \%$ of adults, indicating that it is a major health problem in Europe that needs to be approached more seriously. It appears that about $14 \%$ of patients discontinued analgesic treatment due to side effects, one-third of patients suffered without undergoing treatment, and around $40 \%$ of those patients who received treatment assessed it as inadequate. Less than $20 \%$ of the respondents used various non-drug treatments, e.g., physical therapy, massage and acupuncture, while only $2 \%$ of the surveyed patients were treated by a pain management specialist $[17,18]$. The highest rates of chronic pain prevalence were reported, inter alia, for Poland (27\%), Norway (30\%) and Italy, and the afflicted patients were younger in Poland (mean age: 47 years), Israel and Italy than in other participating countries. In Poland, women with chronic pain dominated (55\%) over men. Severe pain (the Numeric Rating Scale [NRS] a score of $\geq 8$ ) was reported by as many as $31 \%$ of the respondents, while in daily practice only $5 \%$ of these cases were scored by the doctors with pain scales $[17,19]$.

\section{Functional impairment in occupational life}

Chronic nonspecific musculoskeletal pain (CMP), the prevalence of which varies $13-47 \%$, is one of the most widespread disorders generating high costs in occupational medicine and rehabilitation. This financial burden (referring mostly to fibromyalgia [20] or low back pain) is mainly associated with a loss in productivity due to temporary or permanent work disability [21]. Nevertheless, the majority of people suffering from CMP maintain their employment despite experiencing pain. De Vries et al. [22] defined staying at work despite CMP as a healthy coping behavior which would help keep employment, and workers' health and well-being. Reducing emotional distress and perceived physical disability are the identified factors promoting continuing work despite pain.

In contrast, sickness presenteeism [23] is the condition when employees attend work despite their health condition requiring them to take sick leave. In the cross-sectional study based on 3801 employed persons, a tendency for sickness presenteeism was displayed by women, medium working age workers, and people with children. In the occupational sectors, $46 \%$ (the odds ratio [OR] = 2.16, 95\% CI: 1.32-3.55) of persons employed in the education sector, and $44 \%(\mathrm{OR}=1.93,95 \%$ CI: $1.20-3.11)$ of those employed in the care and welfare sector, attended work despite sickness. For professional groups, the highest percentage of this phenomenon was observed among nursing home aides, nursing and midwifery professionals, welfare workers, as well as teachers, pre-primary educationalists and banking officials.

At the same time, the professional groups with high sickness presenteeism demonstrated high sickness absenteeism. The statistical significance $(\mathrm{p}<0.001)$ between sickness presenteeism and symptoms of ill health was obtained for upper back/neck pain and fatigue/mild symptoms of depression. Among the reasons leading to presenteeism, the following are mentioned: a median or lower income level, irreplaceability and work with dependent or vulnerable people.

In Poland, the prevalence of presenteeism was above $23 \%$. However, in Denmark or Malta, it was found to reach even $50 \%$ [24]. Among the health-related causes leading to presenteeism, the following are classified: acute illnesses, 
recurring complaints, chronic disorders and lifestyle factors. It is assumed that the same factors affect absenteeism. Similarly, diseases that most often lead to sick leave (musculoskeletal and gastrointestinal disorders or mental health problems) are listed as the most common with which the employee still decides to go to work. The frequency of sick leave is reduced in cases of self-employment, job insecurity or alternative employment options.

As a consequence, presenteeism can lead to complications such as depression, exhaustion, burnout or poor mental health [25]. Presenteeism and absenteeism were compared and it was shown that the first independently increased the risk of developing moderate to severe exhaustion. The 3 states mentioned above were associated with negative effects on work performance, which was particularly reported by employees with severe exhaustion. It may be surprising that, despite the pressure, professional demands or thoughts of the employee being irreplaceable, not absenteeism but presenteeism brings greater adverse economic consequences.

In the questionnaire-based cross-sectional study [26], which examined the association between neuropathic pain and burnout, the authors showed that both disorders shared congruous risk factors and effects, which may indicate a similar pathophysiology. Work environment, interpersonal and professional conflicts, and emotional distress leading to emotional depletion, detachment from work and reduced productivity are categorized as factors influencing the appearance of occupational burnout. Employees of the following professions participated in the survey: healthcare workers, swabbers, economicaltechnical workers, social workers and teachers. More than half of the respondents reported low back pain, of whom $23.1 \%$ had a neuropathic component. Neuropathic pain was associated with higher age ( $>62$ years) and a larger family ( $>2$ children). Also, employment as a social worker and having an additional job (perhaps due to lower income) was strongly related to a higher risk of neuropathy ( $\mathrm{p}=0.03$ and $\mathrm{p}=0.014$, respectively). Neuropathic low back pain was associated with moderate or severe depression, generalized pain, burnout syndrome, hypertension and diabetes.

In Brazilian studies [6], the authors assessed work productivity and activity impairment in persons with any type of neuropathic pain. From 2118 participants who reported pain lasting $\geq 3$ months in the previous year, almost $15 \%$ were diagnosed with probable neuropathic pain. Females (80.5\%), middle-aged people (52.5 years) with high blood pressure or diabetes predominated in this group. The most commonly reported sensory symptoms were numbness, hyperalgesia, allodynia and impaired vibratory sense. Most often, absence from work concerns patients with post-traumatic neuropathic pain (26.8\%), less frequently with chronic lower back pain with a neuropathic component $(21.7 \%)$, and central neuropathic pain (20.6\%). The highest percentage (68.3-74.6) of presenteeism was observed in cases of central neuropathic pain, post-surgical neuropathic pain and post-traumatic neuropathic pain subtypes. Among those employed, patients with central neuropathic pain (77.1\%) experienced the greatest overall work impairment, while patients with post-surgical neuropathic pain reported the greatest degree of activity impairment (79.6\%).

Low back pain is considered one of the leading causes of disability in the professionally active population. The appearance of this musculoskeletal disease is possibly associated with physiological, mechanical, social, cultural and physiological factors. Up to $80 \%$ of adults experience low back pain at least once in their lifetime and those backaches lead to incapacity and can provoke work absenteeism. In the majority of cases, lower back pain subsides spontaneously after a few to several days. However, there are cases when an employee is on sick leave for several weeks, which represents a significant economic burden. The reasons for differences in work-related absenteeism between individuals have not been established yet; nev- 
ertheless, the research showed a moderate correlation between previous sickness absence and subsequent absenteeism. Perhaps, life satisfaction may prove to be a predictor of sickness absence. However, these results require further research. As the modifying factors, the study reported job satisfaction and social support [27].

Some studies have reported that there is an increased risk of musculoskeletal disorders in people working with computers, which in industrialized countries account for up to two-thirds of employees. The generally accepted consensus is that intensive computer work can cause upper limb pain. However, the relationship between pain and an unequivocal diagnosis remains controversial. Research [28] conducted on 155 computer operators emphasizes the role of neurological examinations for the diagnosis of workrelated upper limb disorders. Previous studies confirmed that those disorders and perceived pain are related to peripheral neuropathy occurring in 3 locations: the infraclavicular brachial plexus, the posterior interosseous nerve, and the median nerve at the elbow level.

Vibrations are mentioned as yet another risk factor for musculoskeletal diseases. While using vehicles, handling machines or construction engines, workers are exposed to whole body vibration, which can lead to the occurrence of lower back pain, degenerative myelopathies or intervertebral disk herniation, which may result in work interruptions or disability. The results of a retrospective study [29] showed that of 93 military high-speed boat pilots, $66.7 \%$ experienced acute pain and $>71 \%$ reported chronic pain linked to professional activity. The most frequently mentioned sites of chronic pain included the lower back (92\%), the neck (83\%), knees (70\%) and the upper back (63\%), where the mean numerical rating scale exceeded 4 . Moreover, among the navy soldiers who suffered from chronic pain, 6 needed to stop working or reported temporary work inability.

Return to work is a complex process which can mean returning to work after a long absence due to illness (sick leave) or returning to work after a period of unemployment. In the meta-ethnography research [30], the authors listed basic obstacles to return to work for people with chronic pain and their employer, which included managing pain and work relationships in the workplace, and making workplace adjustments. These adaptations can positively affect not only relationships with the employer and co-workers but also the entire work environment. Employees are also worried about the employer's expectations and stigmatization. Salary and job security are also underlined. However, the patient's adaptation to the perceived pain, satisfying relationships with health professionals and support seem to a play significant role in regaining working potential. The effectiveness of workplace interventions on work disability varies and depends on the cause of work inability. However, for workers with musculoskeletal disorders, those interventions can reduce pain and sickness absence, as well as improve their functional status [31].

\section{International Classification of Diseases}

The accepted definition of chronic pain as "persistent or recurrent pain lasting longer than 3 months" [12] has not changed since 2015. Despite this fact, until 2019, the diagnosis of "chronic pain" in the International Classification of Diseases (ICD) did not appear regularly [32], which probably influenced the financing of efforts directed against this disease, as well as epidemiological underestimation and incorrect treatment. Likewise, the lack of suitable codes may be affected by the fact that chronic pain may either be a disease or occur as secondary to another disease, in the latter case being considered a symptom.

Chronic primary pain accompanies functional disability and emotional distress, negatively affecting daily functioning, productivity at work and relationships (characterized by a complex interaction of social, psychological, and biological factors) [33]. The above distinctions were included in the ICD classification in the form of "extension codes" for the following evaluators: pain intensity, 
pain-related distress and pain-related interference experienced in the previous week, and determined using the NRS or the Visual Analogue Scale (VAS). The presence of psychosocial factors (cognitive, emotional behavioral and/or social) and temporal characteristic (continuous, episodic recurrent, continuous with pain attack) of pain can also be assessed [2].

The objectives of the new ICD-11 classification are, in addition to establishing a set of clear (clearly operationalized) criteria that would be useful in clinical trials, include creating valid patient and health statistics, as well as reducing cultural stigma $[2,34]$. It is anticipated that due to lifestyle and demographic changes, the prevalence of chronic pain will increase [35].

The reclassification of chronic neuropathic pain prepared by the International Association for the Study of Pain (IASP) in 2019 classifies the most common disorders associated with persistent or recurrent pain lasting for $\geq 3$ months to the following 2 groups: peripheral neuropathic pain and central neuropathic pain. The previous version of ICD-10 required restructuring due to incompleteness or a lack of accuracy, or an incorrect classification of some diseases. The new codes for chronic neuropathic pain will be part of the chronic pain classification, enhance diagnostic reliability and provide transparent criteria.

Pain can appear for various reasons, e.g., disorders, such as metabolic, hereditary and neurodegenerative disorders, but also injuries, tumors and toxins. A group of idiopathic neuropathies can also be found. The intensity of pain and symptoms with the same disease entity differ among patients. However, all such cases require pharmacological and non-pharmacological approaches. It must be noted that pain is a subjective experience and depends on the patient's previous pain sensations, as well as influence of culture and education. Due to experiencing discomfort, it can be associated with an emotional response. Considering that the distribution of pain corresponds with the affected neuroanatomic region, the identification of the lesion or disease involving the nervous system appears necessary $[2,11]$. Electrophysiological tests (nerve conduction studies, somatosensory evoked potentials or laser evoked potentials), imaging and/or nerve biopsy may be helpful in assessing the actual damage and its extent, while questionnaires alone are not diagnostic [15,36]. Moreover, even $92 \%$ of examined patients with different neuropathic pain report $\geq 1$ sensory abnormality [37].

Among common painful neurological disorders encountered in clinical practice, trigeminal neuralgia, chronic neuropathic pain after a peripheral nerve injury, painful polyneuropathy, postherpetic neuralgia and painful radiculopathy belong to a group of chronic peripheral neuropathic pain sensations. In turn, among central neuropathic pains, the following are mentioned: chronic central neuropathic pain associated with a spinal cord injury, chronic central neuropathic pain associated with a brain injury, chronic central poststroke pain, and chronic central neuropathic pain caused by multiple sclerosis [11].

\section{Types of chronic pain}

The correct diagnosis and treatment depend on the origin, duration and exact symptoms of pain. Pain sensations can vary from tingling and numbness to burning pain. It is also important to understand and determine the type of chronic pain which one is dealing with: nociceptive (caused by tissue damage), somatosensory or mixed pain (nociceptive and somatosensory) $[15,38]$.

Neuropathic pain is characterized by damage to the somatosensory neuronal axes. In normal physiological conditions, pain following an injury has a protective and healing effect. However, pathological mechanisms can lead to a chronic spontaneous painful sensation. Additionally, genetic predispositions can lead to the appearance of neuropathic pain after a peripheral nerve injury $[39,40]$. Musculoskeletal pain, e.g., spasticity, is not the same as neuropathic pain [41]; therefore, it is important to distinguish between pain originating from the motor system 
and from the somatosensory system [42]. Perhaps the persistence of peripheral pain despite the healing of tissues is due to abnormal signals at the level of the central nervous system, classified as autonomous mechanisms that generate pain [40]. Conditions of neuropathic pain are divided into 2 broad categories: peripheral neuropathic pain and central neuropathic pain.

The pathology of peripheral disorders - peripheral pain which can occur in various cases of peripheral nerve damage, e.g., infections or inflammation, toxic and mechanical injuries. The presence of somatosensory signs is located in the innervation territory of the injured nerve [43]. This pathology mostly engages the small unmyelinated C-fibres and the myelinated A-fibres, namely, the $A \beta$ and $A \delta$ fibres. Spontaneous pain is usually burning or shooting $[7,11,42]$.

Central pain is caused by illness or damage in the somatosensory system within the central nervous system (CNS). Regardless of the etiology, some clinical features are the same: a complete or partial loss of pinprick and temperature sensation due to the loss of spinothalamic functions and development of hypersensitivity in the affected body parts. Both spontaneous pain and evoked pain, and their combinations, can occur $[11,44]$. Central neuropathic pain may begin months to years after the injury which may hinder the proper identification of the causeand-effect relationship. Its intensity is usually moderate to severe and functionally-limiting [41].

Characteristic and important stages of neuropathic pain include: ectopic activity, peripheral sensitization, central sensitization, impaired inhibitory modulation and activation of microglia [44]. Afferent fibres must be damaged in order for neuropathic pain to develop, but specific mechanisms are not known yet. Those mechanisms may vary in each patient. Spontaneous and shooting pain sensations occur due to the ectopic impulse generation within the nociceptive pathways. Probably, peripheral damage leads to increased expression of sodium channels in damaged and adjacent fibres, and to a decreased action potential threshold and the occurrence of ectopic activity. Changes may also affect other ion channels and upregulation of various receptor proteins (such as the transient receptor potential V1 - TRPV1). Similar changes may secondarily appear in the CNS. In some cases, the CNS itself might not be necessarily engaged, as a consequence of ectopic activity in primary nociceptive afferent fibres or within second-order nociceptive neurons through the expression of voltagegated sodium channels or phosphorylation of $\alpha$-amino3-hydroxy-5-methyl-4-isoxazolepropionic acid (AMPA) and N-methyl-D-aspartate (NMDA) receptors, or by excitatory amino acids and neuropeptides from the dorsal horn, probably also through the reduction of normal $\gamma$-aminobutyric acid (GABA) and glycine inhibition.

After a peripheral nerve injury, the number of inhibitory GABAergic interneurons in the spinal cord also decreases. Hypersensitivity to pain may also be induced by an inflammatory response (cytokine-induced) and an influx of macrophages into the nerve and dorsal root ganglion. The activation of microglia releases the modulators of inflammation that maintain neuropathic pain which may occur in the intact peripheral nerve endings and nociceptors $[15,16,45]$.

\section{Grading system}

The key to suspecting the possibility of neuropathic pain is to analyze the patient's medical history. Non-neuronal tissue damage and the occurrence of only inflammatory factors disqualify the patient from such suspicion. The appearance of pain and its duration vary from several days to several years. Sometimes pain is an exclusive disease symptom although it can appear with autonomic or motor symptoms. Pain description given by the patient (e.g., burning, pricking, tingling), factors that soothe or intensify pain (e.g., touch, temperature changes) and painless sensory symptoms can be pathognomonic. At this stage, neuropathic pain questionnaires may be helpful. 
Questionnaires for assessing neuropathic pain are simple and ready-to-use instruments readily available for specialists and non-specialists in everyday practice and clinical trials. Questionnaires help not only to confirm a suspected possibility of neuropathic pain but also to assess response to treatment (divided into screening and evaluation questionnaires) or to verify the correctness of pharmacotherapy, as neuropathic pain is treated differently depending on each patient and symptoms. However, the scales must be correctly selected and assessed in several aspects, including the quality of life and cognitive impairment. Their use can also help in evaluating the incidence of the disease in the general population and in identifying risk factors. Questions relating to tingling, prickling, and pins and needles are considered "core clinical" common sensory descriptors.

Among the used questionnaires, central neuropathic pain and peripheral neuropathic pain are estimated using the Douleur Neuropathique 4 Questions (DN4), while other questionnaires estimate peripheral neuropathic pain, including the painDETECT Questionnaire, the Neuropathic Pain Questionnaire (NPQ)/NPQ-Short Form, the IDentification Pain Questionnaire, and the Leeds Assessment of Neuropathic Symptoms and Signs (s-LANSS) based on self-reporting. Some scales can be filled by the patients themselves, while some other require specialist examination $[5,15]$. However, one must keep in mind that the questionnaires have their weaknesses and cannot replace the diagnostics carried out by a specialist.

The probability of neuropathic pain is based on a neurological examination that reveals certain sensory impairment such as superficial feeling disturbances, which overlap with neurological damage. The examination must include a study of surface sensation: touch, pain, vibration, cold and heat, where the response to stimuli can be correct, reduced or increased. A positive sensory symptom in the form of hyperesthesia is rarely seen. However, its appearance mask sensory disorders. The final confir- mation of the disease should be based on somatosensory damage confirmed by a diagnostic test, but it cannot exclude alternative diagnosis [42].

\section{Treatment}

Poor response to treatment with available drugs is probably due to the multidirectional pathophysiology of neuropathic pain that requires a multidirectional approach [46]. Moreover, studies have shown that many patients do not receive proper treatment. Various classes of drugs with analgesic and co-analgesic effects were compared with placebo, e.g., non-opioid analgesic drugs, antiepileptics, antidepressants, opioids, local anaesthetic drugs, NMDA receptor antagonists and other agents. Current recommendations have very carefully evaluated pain relief and the possibility of side effects. Classic nonopioid analgesics do not provide satisfactory results.

Recommendations divide current medications into first (a strong recommendation for use), second and third lines (a weak recommendation for use). Among firstline drugs, the following are listed: tricyclic antidepressants (TCAs), serotonin-noradrenaline reuptake inhibitors (SNRIs), pregabalin, gabapentin and extended-release gabapentin/enacarbil. Second-line drugs include lidocaine patches, capsaicin patches and tramadol, and third-line drugs: strong opioids (particularly oxycodone and morphine) and botulinum toxin A. There are no clear indications for the use of combined therapy. In selected cases, if there is no response to previous treatment, polytherapy in the form of combined pregabalin/ gabapentin and duloxetine/TCAs may be attempted. The most important in the selection of appropriate treatment is to assess the patient's concomitant diseases, medication, age and occurrence of potential undesirable effects [44,47] (Table 1).

For antiepileptic drugs, high-quality evidence exists for the use of pregabalin in a dose of 150-600 mg/day (in 2 divided doses) with a satisfactory dose-response 
Table 1. Treatment recommendations in chronic neuropathic pain and chronic pain $[47,49]$

\begin{tabular}{|c|c|c|}
\hline Treatment line & International recommendation & Polish recommendation \\
\hline First line & $\begin{array}{l}\text { antiepileptic drugs } \\
\text { - } \text { pregabalin } 150-600 \mathrm{mg} / \text { day in } 2 \text { divided doses } \\
\text { - gabapentin } 900-3600 \mathrm{mg} / \text { day in } 3 \text { divided doses } \\
\text { - } \text { extended-release gabapentin/enacarbil } 1200-3600 \mathrm{mg} / \text { day } \\
\text { in } 2 \text { divided doses } \\
\text { - carbamazepine or } 0 x \text { carbazepine* } \\
\text { antidepressants (TCAs, SNRls) } \\
\text { - } \text { amitriptyline } 25-150 \mathrm{mg} / \text { day, once a day } \\
\text { or in } 2 \text { divided doses } \\
\text { - duloxetine } 20-120 \mathrm{mg} / \text { day or venlafaxine } 150-225 \mathrm{mg} / \text { day, } \\
\text { once a day } \\
\text { opioids group, weak opioid agonist } \\
\text { - tramadol/extended-release tramadol } \leq 400 \mathrm{mg} / \text { day, } \\
\text { in } 2 \text { or } 3 \text { divided doses }\end{array}$ & $\begin{array}{l}\text { antiepileptic drugs } \\
\text { - pregabalin } 150-600 \mathrm{mg} / \text { day } \\
\text { - carbamazepine } 100-1200 \mathrm{mg} / \text { day once or twice a day } \\
\text { or oxcarbazepine } 300-3000 \mathrm{mg} / \text { day* } \\
\text { antidepressants (TCAs, SNRIs) } \\
\text { - amitriptyline imipramine } \\
\text { - duloxetine } \\
\text { - venlafaxine } \\
\text { topical treatment (patches) } \\
\text { - } 5 \% \text { lignocain, maximum dose } 3 \mathrm{TTS} \text { for } 12-18 \mathrm{~h} / \text { day } \\
\text { an adjunct, to potentiate opioid analgesia } \\
\text { - mianserin } \\
\text { - mirtazapine }\end{array}$ \\
\hline Second line & $\begin{array}{l}\text { topical treatment (patches) } \\
-5 \% \text { lidocaine } 1-3 \text { patches once a day for } \leq 12 \mathrm{~h}^{* *} \\
-8 \% \text { capsaicin } 1-4 \text { patches for } 30-60 \mathrm{~min}\end{array}$ & $\begin{array}{l}\text { opioids group } \\
\text { - } \text { morphine, initially } 10-15 \mathrm{mg} \text { every } 4 \mathrm{~h} \\
\text { or comparable doses of other opioids } \\
\text { - } \text { methadone } \\
\text { - } \text { tramadol, maximum dose } 400 \mathrm{mg} / \text { day } \\
\text { (>75 years old - } 300 \mathrm{mg} / \text { day) } \\
\text { - } \text { buprenorphine }\end{array}$ \\
\hline Third line & $\begin{array}{l}\text { strong opioids } \\
- \text { oxycodone } 10-120 \mathrm{mg} / \text { day } \\
- \text { morphine } 90-240 \mathrm{mg} / \text { day } \\
\text { BTX-A } \\
- \text { single administration of BTX-A in a dose of } 50-200 \text { units } \\
\quad \text { subcutaneously every } 3 \text { months }\end{array}$ & $\begin{array}{l}\text { antiepileptic drugs } \\
\text { - carbamazepine } \\
\text { - oxcarbazepine } \\
\text { - topiramate } \\
\text { - lamotrigine } \\
\text { - valproic acid } \\
\text { other } \\
\text { - bupropion, citalopram, paroxetine, mexiletine, } \\
\quad \text { dextromethorphan, topical capsaicin }\end{array}$ \\
\hline
\end{tabular}

BTX-A - botulinum toxin type A; SNRIs - serotonin-norepinephrine reuptake inhibitors; TCAs - tricyclic antidepressants; TTS - transdermal therapeutic systems.

* Only in trigeminal neuralgia.

** In the case of elderly, lidocaine patches may be influenced in the first line of treatment.

*** In some clinical situations, they may be used as the first line of treatment.

gradient. Sufficient safety but without the dose-response gradient was observed for gabapentin (900-3600 mg daily, in 3 divided doses) and extended-release gabapentin/enacarbil (1200-3600 mg daily, in 2 divided doses). Topiramate, zonisamide, and oxcarbazepine/carbamazepine are not recommended for use because of the poorest safety profile, except for the treatment of trigeminal neuralgia for which it is recommended to use carbamaze- pine or better-tolerated oxcarbazepine. In drug-resistant cases, surgical treatment or gamma-knife nerve root destruction are often used (however, with limited evidence and results).

In the group of antidepressants, TCAs and SNRIs have been best reviewed. For amitriptyline, the final quality of evidence has been moderate for a dose $25-150 \mathrm{mg}$ /day, once a day or in 2 divided doses. High-quality evidence 
has been obtained for duloxetine and venlafaxine in the daily doses of 20-120 mg and 150-225 mg, respectively, administered once a day. The analgesic effect has been proven for patients with and without depression. Additional benefits of these drugs are the treatment of comorbid depression and pain-related sleep disorders.

From the opioids group, almost all examined drugs have a moderate final quality of evidence: weak opioid agonist tramadol/extended-release tramadol ( $\leq 400 \mathrm{mg} /$ day, in 2 or 3 divided doses) and oxycodone (10-120 mg/day), and morphine (90-240 mg/day), as strong opioids in peripheral neuropathies with specific dosage recommendations for each patient.

Topical treatment (patches) with excellent tolerability and safety has been reported for the $5 \%$ lidocaine patch (examined only for a period of $<3$ weeks, $1-3$ patches to the region of pain once a day for $\leq 12 \mathrm{~h}$ ), when used especially for postsurgical neuropathic pain and in postherpetic neuralgia. Sustained efficacy of a single application of a high-concentration capsaicin patch (8\%) was seen in postherpetic neuralgia or HIV-related painful polyneuropathy (1-4 patches to the painful area for 30-60 $\mathrm{min}$ ). In the case of the elderly, lidocaine patches may be included as the first line of treatment (due to the possible occurrence of undesirable effects of oral drugs).

In peripheral neuropathies, it is also acceptable to use a single administration of BTX-A in a dose of 50-200 units subcutaneously (every 3 months) in the painful area. Safety is generally excellent.

Cannabinoids, valproate, levetiracetam and mexiletine are not recommended or are contraindicated for use (recommendations against use) [44,47].

By referring to the recommendations of the Polish Association for the Study of Pain and the Polish Neurological Society $[48,49]$, first-line drugs present on the Polish pharmaceutical market include: amitriptyline and imipramine (TCAs), duloxetine and venlafaxine (SNRIs), pregabalin, gabapentin and carbamazepine or oxcarbazepine, and the $5 \%$ lidocaine patch. As an adjunct, mianserin and mirtazapine can be used to potentiate opioid analgesia. Among opioid drugs, the following are recommended: tramadol (mild to moderate pain), morphine, oxycodone, fentanyl, buprenorphine and methadone (moderate to severe pain). In clinical practice, opioid drugs with analgesic adjuvants, e.g., antidepressants and anticonvulsants, are used. However, there is no clear information as to which opioid is the most effective in neuropathic pain. Treatment begins with the first-line drug with a progressive increase in its dose. Effective analgesic results are understood as pain reduction by at least $50 \%$. If satisfactory efficacy is not achieved despite the use of a sufficiently high dose, or if adverse events occur, the drug should be switched to another substance representing the same group. In the absence of further effects, the drug can be changed to a second or third line of treatment, alone or in combination, in an individually selected way, dosedependent treatment efficacy is often observed.

No efficacy of TCAs treatment was observed in the case of neuropathy in the course of HIV infection, in peripheral neuropathy induced by oncological chemotherapy and after ineffective spinal surgery in radiculopathy. In patients with cardiovascular diseases, amitriptyline in doses of $>100 \mathrm{mg}$ daily is not recommended. While SNRIs have a more favorable safety profile than TCAs, they must be used carefully in patients with cardiovascular disease and sleep disorders.

Gabapentin is recommended for the treatment of diabetic and peripheral neuropathy, in which case the dosedependent treatment efficacy has been seen. However, dizziness and sedation are also likely to appear.

Pregabalin is the drug of choice for neuropathic pain in elderly patients. Pregabalin does not interact with other drugs. It is characterized by linear pharmacokinetics, making it easier to predict its dose-dependent tendency. It is recommended for post-herpetic, diabetic and trigeminal neuralgia, and for persistent postoperative pain. 
In trigeminal neuralgia, it is recommended to use carbamazepine and oxcarbazepine, but the side effects (such as liver damage) are rarely observed in the application of the second drug. Treatment is initiated with small doses once or twice a day, which are then gradually increased until the desired effect is achieved.

Lamotrigine and valproic acid are effective in both peripheral and central neuropathic pain. Lamotrigine may act synergistically with carbamazepine. However, this combination increases the possibility of developing the Stevens-Johnson syndrome. The therapeutic dose for lamotrigine is $400 \mathrm{mg} /$ day. It is achieved on the fourth day of treatment, giving the following doses: $50 \mathrm{mg}-$ $100 \mathrm{mg}-300 \mathrm{mg} /$ day. Valproic acid treatment starts with $300 \mathrm{mg}$ administered at night; then, the dose is increased every 3 days to a maximum dose of $1500 \mathrm{mg} /$ day.

Topical application of capsaicin in patches ( $8 \%$ or $0.004 \%)$ may be considered in the treatment of postherpetic neuralgia, in the course of HIV infection neuropathy and neuropathy after chemotherapy. A single-use patch is used for 30-60 $\mathrm{min}$.

In addition to pharmacological treatment, in selected cases, among others, in the treatment of complex regional pain syndrome or amputated pain, non-pharmacological effects are recommended. Among them the following are mentioned: physiotherapy, occupational therapy and psychological therapy, and less often hypnosis or acupuncture.

Proper treatment of neuropathic pain is aimed, in addition to reducing pain (by 30-50\%), to improve the quality of life and sleep, to improve/recovery, and to maintain work opportunities and everyday life activities [50]. Physical activity is also proposed as it activates the reward system in the brain. Exercise can decrease pain perception, reduce the dose of drugs used, and improve the quality of life by reducing stress and depression. A sedentary and inactive lifestyle can affect the appearance or escalation of chronic pain [51].

\section{Coping strategy}

Research [52] has shown that self-management interventions are a promising possibility to ameliorate communication between all stakeholders (including relations between the patient and the treating physician, family or friends) and, as a result, to improve self-management or self-efficacy strategies (e.g., coping with pain strategy, controlling pain, sustained motivation, distress). In addition, supportive ambiance, cooperation without judging and therapeutic alliance help to make and share decisions, and lead to problem solving. Those interventions may enhance treatment preference decisions, management plans and health outcomes, and are also likely to help patients return to their previous activities.

Finally, cognitive-behavioral treatment, by affecting the patient's self-esteem, is considered a strong factor and a predictor of chronic pain outcome and recovery. Combined cognitive-behavioral management training for pain competence and depressive symptoms is distinguished as another type of the coping strategy, which beside pain competence training positively affects work-related ability (mental and physical work ability) and reduces painrelated days of sick leave. It is particularly addressed to people with high levels of depressive symptoms [53].

The relationship between chronic pain and mental health is bidirectional. Probably, this dependence exists and is partly due to shared neural mechanisms. Chronic pain favors mental health problems as substance abuse, sexual violence and suicide, in addition to existing anxiety disorders and depression (which affects $\leq 20-50 \%$ of cases). Effective treatment consists of pharmacological management and efficacious behavioral interventions (e.g., multidisciplinary pain rehabilitation and cognitive-behavioral therapy) [14,54]. Methods such as hypnosis, relaxation and mindfulness meditation training are also proposed to calm the patient and increase pain tolerance, because attention to painful stimuli is a determinant of response to pain. The patient's adaptive behavior includes mainte- 
Table 2. Cluster characteristics $[43,60]$

\begin{tabular}{|c|c|c|c|c|c|}
\hline \multirow{2}{*}{ Cluster } & \multirow{2}{*}{ Characteristics } & \multirow{2}{*}{$\begin{array}{l}\text { Pathophysiology } \\
\text { of sensory loss }\end{array}$} & \multirow{2}{*}{ Ongoing pain } & \multicolumn{2}{|c|}{ Treatment } \\
\hline & & & & high efficiency & moderate efficiency \\
\hline Cluster 1 & $\begin{array}{l}\text { sensory loss with } \\
\text { paradoxical heat sensation }\end{array}$ & $\begin{array}{l}\text { loss of small and large } \\
\text { fibres }\end{array}$ & $\begin{array}{l}\text { ectopic activity } \\
\text { in damaged nociceptors } \\
\text { or in CNS neurons }\end{array}$ & $\begin{array}{l}\text { - antidepressant } \\
\text { - opioid }\end{array}$ & $\begin{array}{l}\text { - gabapentinoid } \\
\text { - Na-channel blocker }\end{array}$ \\
\hline Cluster 2 & $\begin{array}{l}\text { thermal hyperalgesia with } \\
\text { mild dynamic mechanical } \\
\text { allodynia (mostly } \\
\text { peripheral sensitization) }\end{array}$ & - & $\begin{array}{l}\text { spontaneous activity } \\
\text { in surviving nociceptors }\end{array}$ & - Na-channel blocker & $\begin{array}{l}\text { - antidepressant } \\
\text { - gabapentinoid } \\
\text { - opioid } \\
\text { - topical capsaicin } \\
\text { - botox } \\
\text { - NSAIDs }\end{array}$ \\
\hline Cluster 3 & $\begin{array}{l}\text { mechanical hyperalgesia } \\
\text { with pinprick and } \\
\text { dynamic mechanical } \\
\text { allodynia (mostly central } \\
\text { sensitization) }\end{array}$ & loss of mostly small fibres & $\begin{array}{l}\text { (ectopic?) activity } \\
\text { in nociceptors }\end{array}$ & $\begin{array}{l}\text { - gabapentinoid } \\
\text { - Na-channel blocker }\end{array}$ & $\begin{array}{l}\text { - antidepressant } \\
\text { - opioid } \\
\text { - NMDA-antagonist }\end{array}$ \\
\hline
\end{tabular}

CNS - central nervous system; NMDA - N-methyl-D-aspartate; NSAIDs - non-steroidal anti-inflammatory drugs.

nance used to cope with or manage pain, e.g., social activities and hobbies, which contribute to a decreased pain perception and a better functioning over time [55]. Pain, especially chronic, can also affect mortality by interfering with everyday life (physical limitation, inactivity, poorer health). Additionally, physical activity is inversely and linearly associated with mortality [56,57]. One must pay attention to the possibility of occurrence of psychogenic pain disorder which should not be treated with analgesics, and is most often a mask of depression [58].

\section{Techniques of interventional pain management}

Interventional treatments are indicated in intractable cases of neuropathic pain. These methods of treatment include nerve blockades, epidural steroid injections, radiofrequency neuroablation, intrathecal drug delivery, and peripheral and central neurostimulatory techniques [59].

In literature, more and more space is devoted to phenotype-based therapy rather than to the underlying etiology [60]. This kind of therapy is based on quantitative sensory testing where the standardized battery of stimuli, such as mechanical and thermal stimuli, is used to assess the negative and positive signs in afferent pathways (nociceptive and non-nociceptive). Then, a pathological sensory profile is evaluated based on the patient's results compared with reference values.

The following 3 subgroups were separated:

- sensory loss (with paradoxical heat sensation) - cluster 1,

- thermal hyperalgesia (with mild dynamic mechanical allodynia) - cluster 2 ,

- mechanical hyperalgesia (with pinprick and dynamic mechanical allodynia) - cluster $3[37,43,60]$.

As the main recommended medications, the following are listed:

- oral opioids and antidepressants for cluster 1,

- sodium (Na)-channel blocker (less topical 8\% capsaicin patches and intracutaneous botulinum toxin) for cluster 2,

- gabapentinoid and Na-channel blocker for cluster 3 [60]. Still, the challenge is to develop a clear algorithm and to conduct clinical trials [43] (Table 2). 


\section{RESULTS}

Many studies indicate that people employed in various occupational sectors, e.g., health care and education, may also wrestle with these disease units. Neuropathic pain, more than chronic pain, has an impact on the quality of life, mental health and lost work productivity. Sickness presenteeism and/or absenteeism will not only lead to economic burdens, but also to burnout, fatigue and depression syndromes in employees, which may require specialized effective interventions, including rehabilitation and cognitive-behavioral treatment, or supporting continued engagement in work.

The authors did not find articles concerning total job resignation due to pain, which can be an interesting topic for further research.

\section{CONCLUSIONS}

Chronic pain and neuropathic pain constitute an underestimated and underfunded interdisciplinary problem all over the world. The scale of this problem will continue to increase due to the population aging and the growing incidence of lifestyle disorders. The addition of supplemental criteria for chronic pain and the reclassification of criteria for chronic neuropathic pain aim to improve patient care and treatment, health policy decisions and financing, as well as research on pain and its accurate epidemiology.

Every patient with chronic pain should be treated by adopting a multidisciplinary approach which should lead to a personalized pain management plan. Pain must be correctly assessed by a pain management specialist and its intensity scored at each visit, while the appearance of a sensory deficit must be proven by diagnostic tests. The evaluation of the effectiveness of treatment should be made frequently enough to be verifiable and meaningful. The authors hope that chronic pain will finally be established as an essential health issue.

\section{REFERENCES}

1. Torrance N, Ferguson JA, Afolabi E, Bennett MI, Serpell MG, Dunn KM, et al. Neuropathic pain in the community: More under-treated than refractory? Pain. 2013;154(5):690-9, https://doi.org/10.1016/j.pain.2012.12.022.

2. Treede RD, Rief W, Barke A, Aziz Q, Bennett MI, Benoliel R, et al. Chronic pain as a symptom or a disease: The IASP Classification of Chronic Pain for the International Classification of Diseases (ICD-11). Pain. 2019;160(1):19-27, https://doi.org/10.1097/j.pain.0000000000001384.

3. Dworkin RH, O'Connor AB, Kent J, Mackey SC, Raja SN, Stacey BR, et al. Interventional management of neuropathic pain: NeuPSIG recommendations. Pain. 2013;154(11): 2249-61, https://doi.org/10.1016/j.pain.2013.06.004.

4. Bouhassira D, Lantéri-Minet M, Attal N, Laurent B, Touboul C. Prevalence of chronic pain with neuropathic characteristics in the general population. Pain. 2008;136(3):380-7, https://doi.org/10.1016/j.pain.2007.08.013.

5. Attal N, Bouhassira D, Baron R. Diagnosis and assessment of neuropathic pain through questionnaires. Lancet Neurol. 2018; 17(5):456-66, https://doi.org/10.1016/S1474-4422(18)30071-1.

6. Udall M, Kudel I, Cappelleri JC, Sadosky A, King-Concialdi K, Parsons B, et al. Epidemiology of physician-diagnosed neuropathic pain in Brazil. J Pain Res. 2019;12:243-53, https://doi.org/10.2147/JPR.S160504.

7. Colloca L, Ludman T, Bouhassira D, Baron R, Dickenson AH, Yarnitsky D, et al. Neuropathic Pain. Nat Rev Dis Prim. 2017; 3(Imi):1-45, https://doi.org/10.1038/nrdp.2017.2.

8. Enns MW, Bernstein CN, Kroeker K, Graff L, Walker JR, Lix LM, et al. The association of fatigue, pain, depression and anxiety with work and activity impairment in immune mediated inflammatory diseases. PLoS One. 2018;13(6):118, https://doi.org/10.1371/journal.pone.0198975.

9. Harden N, Cohen M. Unmet needs in the management of neuropathic pain. J Pain Symptom Manage. 2003;25(5 Suppl): 12-7, https://doi.org/10.1016/S0885-3924(03)00065-4.

10. Liberati A, Altman DG, Tetzlaff J, Mulrow C, Gøtzsche PC, Ioannidis JPA, et al. The PRISMA statement for reporting 
systematic reviews and meta-analyses of studies that evaluate healthcare interventions: explanation and elaboration. BMJ. 2009;339, https://doi.org/10.1136/bmj.b2700.

11. Scholz J, Finnerup NB, Attal N, Aziz Q, Baron R, Bennett MI, et al. The IASP classification of chronic pain for ICD-11: chronic neuropathic pain. Pain. 2019;160(1):53-9, https://doi.org/10.1097/j.pain.0000000000001433.

12. Treede RD, Rief W, Barke A, Aziz Q, Bennett MI, Benoliel R, et al. A classification of chronic pain for ICD-11. Pain. 2015;156(6):1003-7, https://doi.org/10.1097/j.pain.000000 0000000160.

13. Steingrímsdóttir ÓA, Landmark T, Macfarlane GJ, Nielsen CS. Defining chronic pain in epidemiological studies: A systematic review and meta-analysis. Pain. 2017;158(11):2092-107, https://doi.org/10.1097/j.pain.0000000000001009.

14. Mills SEE, Nicolson KP, Smith BH. Chronic pain: a review of its epidemiology and associated factors in populationbased studies. Br J Anaesth. 2019;123(2):e273-83, https:// doi.org/10.1016/j.bja.2019.03.023.

15. Baron R, Binder A, Wasner G. Neuropathic pain: Diagnosis, pathophysiological mechanisms, and treatment. Lancet Neurol. 2010;9(8):807-19, https://doi.org/10.1016/S14744422(10)70143-5.

16. Jensen TS, Finnerup NB. Allodynia and hyperalgesia in neuropathic pain: Clinical manifestations and mechanisms. Lancet Neurol. 2014;13(9):924-35, https://doi.org/10.1016/ S1474-4422(14)70102-4.

17. Breivik H, Collett B, Ventafridda V, Cohen R, Gallacher D. Survey of chronic pain in Europe: Prevalence, impact on daily life, and treatment. Eur J Pain. 2006;10:287-333, https://doi.org/10.1016/j.ejpain.2005.06.009.

18. St. John Smith E. Advances in understanding nociception and neuropathic pain. J Neurol. 2018;265(2):231-8, https:// doi.org/10.1007/s00415-017-8641-6.

19. Breivik EK, Bjørnssson GA Skovlund E. A Comparison of Pain Rating Scales by Sampling From Clinical Trial Data. Clin J Pain 2000. 2000;16:22-8, https://doi.org/10.1097/00 002508-200003000-00005.
20. White LA, Birnbaum HG, Kaltenboeck A, Tang J, Mallett D, Robinson RL. Employees with fibromyalgia: Medical comorbidity, healthcare costs, and work loss. J Occup Environ Med. 2008;50(1):13-24, https://doi.org/10.1097/JOM. 0b013e31815cff4b.

21. Soer R, De Vries HJ, Brouwer S, Groothoff JW, Geertzen JH, Reneman MF. Do workers with chronic nonspecific musculoskeletal pain, with and without sick leave, have lower functional capacity compared with healthy workers? Arch Phys Med Rehabil. 2012;93(12):2216-22, https:/doi.org/ 10.1016/j.apmr.2012.06.023.

22. De Vries HJ, Reneman MF, Groothoff JW, Geertzen JHB, Brouwer S. Factors promoting staying at work in people with chronic nonspecific musculoskeletal pain: A systematic review. Disabil Rehabil. 2012;34(6):443-58, https://doi. org/10.3109/09638288.2011.607551.

23. Aronsson G, Gustafsson K, Dallner M. Sick but yet at work. An empirical study of sickness presenteeism. J Epidemiol Community Health. 2000;54(7):502-9, https://doi.org/10. 1136/jech.54.7.502.

24. Kinman G. Sickness presenteeism at work: Prevalence, costs and management. Br Med Bull. 2019;129(1):107-16, https://doi.org/10.1093/bmb/ldy043.

25. Aboagye E, Björklund C, Gustafsson K, Hagberg J, Aronsson G, Marklund S, et al. Exhaustion and Impaired Work Performance in the Workplace: Associations with Presenteeism and Absenteeism. J Occup Environ Med. 2019;61(11):E43844, https://doi.org/10.1097/JOM.0000000000001701.

26. Mák K, Kapus K, Tóth G, Hesszenberger D, Pohl M, Pusch G, et al. Neuropathic low back pain and burnout among hungarian workers. Int J Environ Res Public Health. 2021;18(5): 1-10, https://doi.org/10.3390/ijerph18052693.

27. Rolli Salathé C, Melloh M, Mannion AF, Tamcan Ö, Müller U, Boos N, et al. Resources for preventing sickness absence due to low back pain. Occup Med (Chic Ill). 2012;62(4):273-80, https://doi.org/10.1093/occmed/kqs024.

28. Jepsen KR, Thomsen GF, Jepsen JR. A cross-sectional study of the upper limb non-neurogenic physical findings in 
computer operators and their relation to pain and neurological findings. Int J Occup Med Environ Health. 2021;34(5): 679-91, https://doi.org/10.13075/ijomeh.1896.01734.

29. Hurpin V, Peyrefitte S, Ruby X, Daniel Y. Musculoskeletal diseases among French military high-speed boat pilots. Arch Environ Occup Heal. 2020;0(0):1-9, https://doi.org/ 10.1080/19338244.2020.1841720.

30. Grant M, O-Beirne-Elliman J, Froud R, Underwood M, Seers K. The work of return to work. Challenges of returning to work when you have chronic pain: A meta-ethnography. BMJ Open. 2019;9(6):1-14, https://doi.org/10.1136/ bmjopen-2018-025743.

31. van Vilsteren M, van Oostrom SH, de Vet HCW, Franche RL, Boot CRL, Anema JR. Workplace interventions to prevent work disability in workers on sick leave. Cochrane Database Syst Rev. 2015;2015(10), https://doi.org/10.1002/14651858. CD006955.pub3.

32. Finnerup NB, Scholz J, Attal N, Baron R, Haanpää M, Hansson $\mathrm{P}$, et al. Neuropathic pain needs systematic classification. Eur J Pain (United Kingdom). 2013;17(7):953-6, https:// doi.org/10.1002/j.1532-2149.2012.00282.x.

33. Nicholas M, Vlaeyen JWS, Rief W, Barke A, Aziz Q, Benoliel $\mathrm{R}$, et al. The IASP classification of chronic pain for ICD-11: Chronic primary pain. Pain. 2019;160(1):28-37, https://doi.org/10.1097/j.pain.0000000000001390.

34. Katz J, Rosenbloom BN, Fashler S. Chronic pain, psychopathology, and DSM-5 somatic symptom disorder. Can J Psychiatry. 2015;60(4):160-7, https://doi.org/10.1177/070 674371506000402.

35. Arendt-Nielsen L, Morlion B, Perrot S, Dahan A, Dickenson A, Kress HG, et al. Assessment and manifestation of central sensitisation across different chronic pain conditions. Eur J Pain (United Kingdom). 2018;22(2):216-41, https:// doi.org/10.1002/ejp.1140.

36. Haanpää ML, Backonja MM, Bennett MI, Bouhassira D, Cruccu G, Hansson PT, et al. Assessment of Neuropathic Pain in Primary Care. Am J Med. 2009;122(10 Suppl):S13-21, https://doi.org/10.1016/j.amjmed.2009.04.006.
37. Maier C, Baron R, Tölle TR, Binder A, Birbaumer N, Birklein F, et al. Quantitative sensory testing in the German Research Network on Neuropathic Pain (DFNS): Somatosensory abnormalities in 1236 patients with different neuropathic pain syndromes. Pain. 2010;150(3):439-50, https://doi. org/10.1016/j.pain.2010.05.002.

38. Wang VC, Mullally WJ. Pain Neurology. Am J Med. 2020;133(3): 273-80, https://doi.org/10.1016/j.amjmed.2019.07.029.

39. Vollert J, Maier C, Attal N, Bennett DLH, Bouhassira D, EnaxKrumova EK, et al. Stratifying patients with peripheral neuropathic pain based on sensory profiles: Algorithm and sample size recommendations. Pain. 2017;158(8):1446-55, https:// doi.org/10.1097/j.pain.0000000000000935.

40. Meacham K, Shepherd A, Mohapatra DP, Haroutounian S. Neuropathic Pain: Central vs. Peripheral Mechanisms. Curr Pain Headache Rep. 2017;21(6), https://doi.org/10.1007/s119 16-017-0629-5.

41. Putzke JD, Richards JS, Hicken BL, Ness TJ, Kezar L, DeVivo M. Pain classification following spinal cord injury: The utility of verbal descriptors. Spinal Cord. 2002;40(3): 118-27, https://doi.org/10.1038/sj.sc.3101269.

42. Finnerup NB, Haroutounian S, Kamerman P, Baron R, Bennett DLH, Bouhassira D, et al. Neuropathic pain: An updated grading system for research and clinical practice. Pain. 2016;157(8):1599-606, https://doi.org/10.1097/j.pain.0000 000000000492.

43. Baron R, Maier C, Attal N, Binder A, Bouhassira Di, Cruccu G, et al. Peripheral neuropathic pain: A mechanismrelated organizing principle based on sensory profiles. Pain. 2017;158(2):261-72, https://doi.org/10.1097/j.pain.000000 0000000753.

44. Gilron I, Baron R, Jensen T. Neuropathic pain: Principles of diagnosis and treatment. Mayo Clin Proc. 2015;90(4):53245, https://doi.org/10.1016/j.mayocp.2015.01.018.

45. Dubin AE, Patapoutian A. Nociceptors: the sensors of the pain pathway Find the latest version: Review series Nociceptors: the sensors of the pain pathway. J Clin Invest. 2010;120(11):3760-72, https://doi.org/10.1172/JCI42843. 
46. Bouhassira D, Attal N. Diagnosis and assessment of neuropathic pain: The saga of clinical tools. Pain. 2011;152(3 Suppl): S74-83, https://doi.org/10.1016/j.pain.2010.11.027.

47. Finnerup NB, Attal N, Haroutounian S, McNicol E, Baron R, Dworkin RH, et al. Pharmacotherapy for neuropathic pain in adults: Systematic review, meta-analysis and updated NeuPSig recommendations. Lancet Neurol. 2015;14(2): 162-73, https://doi.org/10.1016/S1474-4422(14)70251-0.

48. Szczudlik A, Dobrogowski J, Wordliczek J, Stępień A, Krajnik M, Leppert W, et al. Rozpoznanie i leczenie bólu neuropatycznego: przegląd piśmiennictwa i zalecenia Polskiego Towarzystwa Badania Bólu i Towarzystwa Neurologicznego - część druga. Ból. 2014;15(3):5-18, https://doi. org/10.5604/1640324x.1117109. Polish.

49. Szczudlik A, Dobrogowski J, Wordliczek J, Stępień A, Krajnik M, Leppert W, et al. Rozpoznanie i leczenie bólu neuropatycznego: przegląd piśmiennictwa i zalecenia Polskiego Towarzystwa Badania Bólu i Towarzystwa Neurologicznego - część pierwsza: Diagnosis and Management of Neuropathic Pain: Review of Literature and Recommendations of the. Ból. 2014;15(2):8-18, https://doi.org/10.5604/ 1640324x.1115164. Polish.

50. Binder A, Baron R. The pharmacological therapy of chronic neuropathic pain. Dtsch Arztebl Int. 2016;113(37):616-25, https://doi.org/10.3238/arztebl.2016.0616.

51. Lima LV, Abner TSS, Sluka KA. Does exercise increase or decrease pain? Central mechanisms underlying these two phenomena. J Physiol. 2017;595(13):4141-50, https://doi. org/10.1113/JP273355.

52. Devan H, Hale L, Hempel D, Saipe B, Perry MA. What Works and Does Not Work in a Self-Management Intervention for People With Chronic Pain? Qualitative Systematic
Review and Meta-Synthesis. Phys Ther. 2018;98(5):381-97, https://doi.org/10.1093/ptj/pzy029.

53. Hampel P, Köpnick A, Roch S. Psychological and work-related outcomes after inpatient multidisciplinary rehabilitation of chronic low back pain: A prospective randomized controlled trial. BMC Psychol. 2019;7(1):1-10, https://doi. org/10.1186/s40359-019-0282-3.

54. Hooten WM. Chronic Pain and Mental Health Disorders: Shared Neural Mechanisms, Epidemiology, and Treatment. Mayo Clin Proc. 2016;91(7):955-70, https://doi.org/10.1016/ j.mayocp.2016.04.029.

55. Jensen MP. Psychosocial approaches to pain management: An organizational framework. Pain. 2011;152(4):717-25, https://doi.org/10.1016/j.pain.2010.09.002.

56. Smith D, Wilkie R, Croft P, Parmar S, McBeth J. Pain and mortality: Mechanisms for a relationship. Pain. 2018;159(6): 1112-8, https://doi.org/10.1097/j.pain.0000000000001193.

57. Warburton DER, Nicol CW, Bredin SSD. Health benefits of physical activity: the evidence. CMAJ. 2006;174:801-9, https://doi.org/10.1503/cmaj.051351.

58. Shetty P, Mane A, Fulmali S, Uchit G. Understanding masked depression: A Clinical scenario. Indian J Psychiatry. 2018;60(1):97-102, https://doi.org/10.4103/psychiatry.Indian JPsychiatry_272_17.

59. Szok D, Tajti J, Nyári A, Vécsei L. Therapeutic Approaches for Peripheral and Central Neuropathic Pain. Behav Neurol. 2019;2019, https://doi.org/10.1155/2019/8685954.

60. Forstenpointner J, Otto J, Baron R. Individualized neuropathic pain therapy based on phenotyping: are we there yet? Pain. 2018;159(3):569-75, https://doi.org/10.1097/j.pain.00 00000000001088.

This work is available in Open Access model and licensed under a Creative Commons Attribution-NonCommercial 3.0 Poland License - http://creativecommons.org/ licenses/by-nc/3.0/pl/deed.en. 